\title{
¿Etnoturismo o turismo indígena?
}

DOI: 10.22403/UQROOMX/TYP05/09

Magdalena Morales González*

Resumen

En este artículo se aborda la diferencia conceptual entre etnoturismo y turismo indígena, con la finalidad de comprender dos caracterizaciones que aparentemente quieren decir lo mismo, pero que expresan dos modalidades distintas. La primera se refiere a las diversas actividades que pueden realizar los turistas y sus alcances por medio del encuentro con pueblos indígenas; la segunda alude a la construcción participativa de las etnias para ofrecer servicios turísticos, consensuados mediante encuentros, acuerdos y cumbres locales, nacionales e internacionales, buscando interactuar con los visitantes de una manera crítica y responsable, solidaria con la naturaleza y con su identidad cultural.

El turismo indígena es una organización empresarial de autogestión de los recursos patrimoniales comunitarios basada en las prácticas democráticas y solidarias de trabajo para la distribución de los beneficios generados, que se ha desarrollado en América Latina desde los años ochenta. A través de sus acuerdos, se han creado redes que permiten intercambiar experiencias y conocimientos entre comunidades para el apoyo en el mercadeo y la promoción de los distintos destinos turísticos, entre otros aspectos.

Palabras |ldentidad cultural, turismo indígena.

CLAVE

*Instituto Politécnico Nacional, Escuela Superior de Turismo / magdamorgon@hotmail.com 
¿Etnoturismo o

turismo indígena?

\section{Introducción}

Por medio de las nuevas tecnologías, el mundo globalizado ha acortado las distancias y ahora es posible hacer de los viajes una práctica masiva y accesible, de gran importancia en nuestros días; pero no todo el turismo tiene las mismas características. Por ejemplo, los viajes por interés lúdico son aquellos que permiten practicar nuevas experiencias en sitios distintos a los cotidianos, aportan conocimientos y abren otras formas de comprender la realidad; por su parte, en los viajes selectivos (no masivos), llamados temáticos, los turistas buscan travesías en formas disímiles y estar en contacto directo con la naturaleza, con la comunidad anfitriona, con los demás turistas y, principalmente, consigo mismos.

Se puede comprender al turismo desde distintas aristas: los viajeros (turistas), el sector turismo (micro, pequeñas, medianas y grandes empresas turísticas), el medio ambiente, la comunidad anfitriona - que puede ser urbana o rural-y las microempresas de servicios turísticos de las comunidades locales. En este trabajo se asientan algunas reflexiones acerca de las microempresas rurales de servicios turísticos desde el punto de vista de los pueblos indígenas -lo que en sus propias palabras llaman turismo indígena-, y se pretende establecer en lo general la diferencia conceptual entre etnoturismo (una explicación institucional brindada por la Secretaría de Turismo, Sectur) y turismo indígena.

Se mencionan algunos acuerdos logrados en diversas reuniones indígenas, en especial acerca de sus necesidades y peticiones a distintos sectores de la sociedad. Finalmente se presentan los acuerdos parciales alcanzados en varias reuniones de trabajo y aquellos obtenidos en el taller de la Red Indígena de Turismo de México,A.C. (RITA), llevado a cabo el mes de agosto del 2007, en Xochitlán, Puebla, y en octubre de ese año en Edzná, Campeche. Esta red busca que el turismo indígena sea una experiencia de viaje singular, donde el turista, la comunidad anfitriona y la naturaleza formen una unidad participativa para conservar y proteger a los pueblos indígenas dentro de sus regiones ambientales y su cosmovisión ancestral.

\section{Antecedentes}

La conceptualización del turismo indígena aquí expuesta surge de la asistencia a las reuniones periódicas de la RITA, la cual congrega a más de 50 microempresas 
del centro y sureste del país y la cual ha establecido convenios con otras redes latinoamericanas. RITA lleva trabajando aproximadamente cinco años y se financia con recursos económicos que obtiene de organismos nacionales e internacionales.

\section{Metodología}

Este trabajo consiste en una revisión documental acerca de la noción etnoturismo. Se expone el concepto de turismo indígena -producto de la construcción participativa en las reuniones de trabajo de la RITA, donde han intervenido diferentes etnias del país y han acudido invitados académicos pertenecientes a universidades públicas-, y se usan indistintamente los términos indígena, indio y aborigen, ya que, para la antropología, son equivalentes y no cambia su esencia.

\section{Etnoturismo}

La Secretaría de Turismo define al turismo rural como "el lado más humano del turismo alternativo, es el encuentro con las diferentes formas de vivir de las comunidades rurales y que, además, sensibiliza sobre el respeto y su identidad cultural" (Sectur, 2004). Esto es, los viajes que tienen como fin realizar actividades de convivencia e interacción con una comunidad rural, en todas sus expresiones sociales, culturales y productivas cotidianas. Y dice que:

En el turismo rural, el turista no es un visitante-observador en un día de paseo, es una persona que forma parte activa de la comunidad durante su estancia en ella, en donde aprende a preparar alimentos habituales, crea artesanía para su uso personal, aprende lenguas ancestrales, el uso de plantas medicinales, cultiva y cosecha lo que cotidianamente consume, es actor en los eventos tradicionales de la comunidad, percibe y aprecia creencias religiosas y paganas (Sectur, 2004).

Además, la Sectur (2004) enumera nueve actividades que pueden practicarse en este segmento turístico:

I. Etnoturismo: son los viajes relacionados con los pueblos indígenas y su hábitat, con el fin de aprender de su cultura y tradiciones.

2. Agroturismo: concierne a los viajes en las áreas agropecuarias con sociedades campesinas que comparten su idiosincrasia, sus técnicas agrícolas, su entorno natural en conservación, sus manifestaciones culturales y 
socioproductivas, en donde se busca que esta labor represente una alternativa para lograr que el campesino se beneficie con su actividad económica, mediante la combinación de la agricultura y el turismo.

3. Talleres gastronómicos: consisten en aprender, preparar y degustar la variedad culinaria que ofrecen los anfitriones de los lugares visitados.

4. Vivencias místicas: es la experiencia de conocer y participar en la riqueza de las creencias, leyendas y rituales espirituales de un pueblo, heredados de sus antepasados.

5. Aprendizaje de dialectos: aprender el dialecto del lugar visitado, así como sus costumbres y organización social.

6. Ecoarqueología: es decir, los viajes a zonas arqueológicas que implican conocer las relaciones entre el hombre y su medio ambiente en el pasado, partiendo de los restos materiales que ha dejado, y su importancia actual como forma de identidad cultural y conservación ambiental.

7.Preparación y uso de medicina tradicional: permite conocer y participar en el rescate de la preparación y el uso de la medicina tradicional.

8. Talleres artesanales: se refieren a la elaboración de artesanías en los escenarios y con los procedimientos autóctonos.

9. Fotografia rural: esto es, capturar en imágenes las diferentes manifestaciones culturales y paisajes naturales del ambiente rural.

Como se puede observar, la Secretaría de Turismo explica al turismo rural tomando como eje a los turistas que, como viajeros, adquieren experiencias y vivencias. Este enfoque, si bien define las distintas posibilidades que ofrecen las áreas rurales, queda fragmentado al considerar únicamente al turista, dejando fuera del escenario a las comunidades campesinas y a los pueblos indígenas, que son los agentes sociales del servicio turístico, de los conocimientos transmitidos en las diversas actividades, del trabajo especializado para socializarlo con los viajeros y de la preservación y difusión de su identidad cultural. Pero es posible explicar el turismo rural, al turismo indígena, con otra perspectiva, desde adentro, como expresión del pensamiento, la reflexión y la acción de los pueblos indígenas; conceptuándolo desde la construcción participativa de los servicios que se pueden ofrecer al turista.

Por ello, las distintas etnias han llevado a cabo diversos actos locales, estatales, nacionales, latinoamericanos y mundiales con objeto de construir nuevas 
formas de trabajo comunitario para la defensa de su identidad cultural, promoviendo distintas actividades económicas, políticas, sociales y culturales que les permitan rescatar y defender a sus etnias de la globalización; una de ellas es la participación de microempresas en el turismo alternativo, denominado turismo indígena, con una misión y una visión acordes con sus raíces culturales.

A continuación se presentan algunas aportaciones que diversas organizaciones han planteado en foros interétnicos para fortalecerse como pueblos indígenas en la defensa permanente del rescate de su cultura, de su cosmovisión y de su espiritualidad, rescate vinculado a actividades que les permitan continuar con su trabajo y con distintas alternativas de éste en las áreas rurales.

\section{Los pueblos indígenas}

Los pueblos indígenas se caracterizan por mantener una profunda relación con lo sagrado, con la naturaleza y con el cosmos. Sus centros ceremoniales fueron destruidos y algunos quedaron ocultos por los fenómenos naturales. En la mayoría de los casos, la cultura dominante los expropió con fines turísticos, de investigación histórica o arqueológica; pero hubo lugares sagrados que se conservaron: como los cerros, manantiales, ríos, milpas y el fogón de los hogares, los cuales hasta la fecha son utilizados para preservar su herencia milenaria, transmitida de generación en generación.

En los años setenta se fortaleció la lucha india por su liberación y, a raíz de su conciencia como pueblos dominados -no sólo en lo económico-social y político sino también en lo educativo y en lo cultural-, las organizaciones, al igual que algunos pueblos indios, comenzaron a reivindicar el derecho a promover y desarrollar su cultura, y mantuvieron una posición de rechazo a la folclorización y explotación de la cultura india por grupos o intereses ajenos, pues se encuentran cada vez más presionados a convertir sus tierras, territorios y tradiciones en artículos de consumo para el turismo tradicional.

La Organización de las Naciones Unidas (ONU) firmó una Declaración en la que expone sus intenciones para corregir el camino y lograr que su normativa se adecue a las situaciones vigentes, y reconoce la paupérrima condición en que viven millones y millones de indígenas en el mundo.' La Declaración fue

'El camino recorrido de los pueblos indígenas para ser escuchados, reconocidos y respetados 
¿Etnoturismo o

turismo indígena?

aprobada por el Consejo de Derechos Humanos, pero aún falta la aprobación final y su adopción por la Asamblea General de la ONU, donde se necesitan los votos de aquellos Estados que siempre se han opuesto al derecho a la autodeterminación de los pueblos indígenas -Estados Unidos, Canadá, Inglaterra y Australia, principalmente-, es decir, países ricos que tienen interés en seguir explotando los recursos naturales que hay en territorios indígenas.

Algunos de los principales encuentros interétnicos en los cuales se han establecido declaraciones y acuerdos son:

- Primer Encuentro de Nacionalidades Indígenas, convocado en 1989. Ahí se acordó impulsar la unidad del Pueblo Otomí, y se convocó a la Primera Reunión Nacional del Pueblo Ñähñu (otomí), en 1990.

- Primer Encuentro Continental de Pueblos Indios, realizado en Quito, Ecuador, en 1990.

- Campaña Continental de Resistencia Indígena, Negra y Popular de los 500 años, que abarcó movilizaciones en todo nuestro continente el 12 de octubre de 1992.

- Segundo Encuentro Continental de Naciones, Pueblos y Organizaciones Indígenas, del 8 al 12 de octubre de 1993, celebrado en el Centro Ceremonial Otomí. La Nación Otomí fue anfitriona y convocante y se firmó la Declaración de Temoaya.

- Primer Congreso Estatal de Pueblos Indios, celebrado en julio de 1994, y del cual la Nación Otomí fue anfitriona; ahí se conformó el Consejo Estatal de Pueblos y Organizaciones Indias (CEPOI), que en diciembre de ese mismo año asistió a la Convención Nacional Indígena.

- Reunión Constitutiva de la Asamblea Nacional Indígena Plural por la Autonomía, ANIPA (abril de 1995).

- Encuentros regionales juveniles otomíes y Primer Encuentro Nacional de la Juventud Otomí, organizado por el Congreso Nacional Otomí (Conao) durante 1995.

por los Estados ha sido largo. Fue hasta 1994 cuando la ONU proclamó oficialmente el Decenio Internacional de las Poblaciones Indígenas del Mundo, conforme el cual reconoce el valor y la diversidad de las culturas y las formas de organización social de esas poblaciones y su contribución al progreso socioeconómico, cultural y ecológico de todas las naciones. 
- Congreso Nacional Indígena, celebrado en 1996, cuyo objetivo fue promover el desarrollo humano y comunitario indígena.

- Primer Foro Latinoamericano sobre Legislación y Derechos Indios en el Congreso Local de la LIII Legislatura del Estado de México, organizado por el Conao en 1998.

- I Cumbre Indígena en Teotihuacan, México (2000).

- La ONU declaró al 2002 como el Año Internacional del Ecoturismo (AIE), pero la poca participación indígena en la planificación de sus actividades causó preocupación entre varios organismos, redes y grupos comunitarios, por lo que la organización Derechos Indígenas del Turismo Internacional (ITRI, por sus siglas en inglés) impulsó el Foro Internacional sobre el Turismo Indígena, en Oaxaca, en marzo del 2002, como una alternativa y un espacio necesario donde los pueblos indígenas han podido conducir una revisión crítica de sus experiencias con el ecoturismo.

- Il Cumbre Continental de Pueblos y Nacionalidades Indígenas del Abya Yala, ${ }^{2}$ que tuvo lugar en Quito, Ecuador, en 2004.

- Cumbre Continental de Pueblos y Organizaciones Indígenas, realizada en Mar del Plata, Argentina, en 2005.

- Encuentro Continental de Pueblos y Nacionalidades Indígenas del Abya Yala, en La Paz, Bolivia, en 2006.

- III Cumbre Continental de Pueblos y Nacionalidades Indígenas del Abya Yala, celebrada en Guatemala en marzo de 2007, de la cual emanó la Declaración de Iximche.

${ }^{2}$ Abya Yala es una institución privada sin fines de lucro con 25 años de labor en el ámbito indígena latinoamericano. Comenzó sus actividades en 1975 y fue aprobada oficialmente el 15 de mayo de 1986. Sus finalidades son: I) Rescatar, documentar y difundir los valores culturales de los pueblos indígenas. 2) Sensibilizar a la sociedad sobre la situación indígena en todos sus aspectos: jurídicos, territoriales, educativos, etc. 3) Promover iniciativas académicas que enriquezcan el debate sobre la cuestión indígena y sus derechos, mediante publicaciones, centros de documentación, congresos, simposios y centros universitarios y académicos. El Centro Cultural Abya Yala acompaña, asesora y coordina a un sinnúmero de personas dedicadas a promover el respeto a los derechos $y$ a los valores indígenas. Abya Yala es el término étnico con el cual los cuna (Panamá) denominan al continente americano en su totalidad. La elección de este nombre (que significa "tierra en plena madurez") fue sugerida por el líder aymara Takir Mamani, quien propone que todos los indígenas lo utilicen en sus documentos y declaraciones orales. 
¿Etnoturismo o

turismo indígena?

Las organizaciones indias consideran que la recuperación de la identidad étnica y la defensa de los valores culturales propios son parte de su proceso de descolonización y liberación, por ello demandaron la creación de sitios como el Centro Ceremonial Mazahua (inaugurado en 1977) y el Centro Ceremonial Otomí (construido a mediados de los setenta), vinculados con el derecho a la autodeterminación, a la autogestión, al territorio, a la organización propia, a la recuperación histórica y al desarrollo cultural.

Una de las conclusiones del Tercer Congreso Nacional de Pueblos Indígenas fue que se modificara la comercialización o utilización del patrimonio cultural indio por grupos ajenos, ya que atenta contra su dignidad. Pidieron al gobierno "respeto" y "defensa" de la cultura india, y que no fuera sólo discurso, por lo que era necesario que el Estado cambiara sus políticas sobre las culturas originarias, para que fueran respetadas, reconocidas y no agredidas culturalmente.

En el Primer Seminario Nacional de Educación Bilingüe-Bicultural (ANPIBAC, 1979) se planteó la necesidad de recuperar la filosofía propia que permitiera revaluar la cultura y concientizar al indio sobre sus necesidades económicas, sociales, culturales y políticas, así como encontrar y lograr la autodefinición étnica y de clase, como requisito para destruir las distintas formas de opresión y explotación que sufren los pueblos originarios. También se alertó sobre no confundirse con las prácticas de asimilación, incorporación e integracionismo del Estado, que son el marco ideológico dentro del cual la clase dominante, heredera del colonizador, pone de relieve la universalidad de su propia cultura y rebaja las aspiraciones de movilidad ascendente del indígena a términos individuales y no colectivos; igualmente se rechazaron las prácticas de destrucción cultural como mecanismo de despojo de las tierras comunales y bosques.

Además se señaló que no puede hablarse de conciencia nacional-negando que México sea una nación multiétnica y pluricultural-, ni tampoco de una cultura nacional, negando el pasado histórico y la presencia actual de las diversas culturas étnicas. Los pueblos indígenas se oponen a ser vistos como curiosidades antropológicas o como objetos de museo; por el contrario, se asumen como seres humanos que piensan y sienten, que poseen una identidad cultural que reclama respeto, y que se encuentran en una realidad socioeconómica de explotación que requiere ser abolida. Proponen recuperar su etnicidad, su identidad histórica y, con ello, su proceso de liberación. 
En la Carta Abierta a los Hermanos Indios de América, en 1980, los pueblos indios del Estado de México recomiendan a las distintas organizaciones indias de América la creación de centros culturales directamente administrados por ellos, en los cuales se concentre todo el conocimiento existente sobre cada pueblo y se impulsen estudios e investigaciones socioculturales; $y$ que desde estos lugares se defiendan y difundan los valores culturales y se les imprima un desarrollo para sacarlos del estancamiento en el cual los hundió el colonialismo. Pero aclaran que exigir respeto a las tradiciones no significa quedarse en el conservacionismo, en el estancamiento cultural o en la pobreza; esto es, si se quiere modificar la situación de sometimiento que se vive, también debe cambiar la cultura india, tomando en cuenta que ésta evolucionó aceleradamente hasta la época de la Conquista, cuando fue dominada y reprimida; por ello la importancia del desarrollo cultural, que fortalezca la identidad india en el presente.

La Declaración de Quito en 2004, en la II Cumbre Continental de Pueblos y Nacionalidades Indígenas del Abya Yala (Bonilla, 2004), establece que las mujeres son la fuente del orgullo cultural y preservadoras de la cultura nativa tradicional a través del hemisferio. Se reclamó que la educación en territorios indígenas tenga como base la filosofía y la opinión de la gente indígena, demandando a los Estado-nación el apoyo a la instrucción indígena en sus propios idiomas, cosmovisión y centros culturales. En la III Cumbre Continental de Pueblos y Nacionalidades Indígenas del Abya Yala se determinó dar cuerpo, vida y movimiento a una instancia de carácter continental que les permitiera la integración y la unidad, fundada en la riqueza espiritual, moral, combativa y de resistencia, con el objetivo primordial de defender a los pueblos y al planeta entero de los ataques protagonizados principalmente por el imperio norteamericano, consolidando espacios de formación que preserven su identidad, cultura, idioma y prácticas de medicina tradicional, de acuerdo con las necesidades de cada pueblo, con múltiples sedes en todo el continente.

Por su parte, en la Cumbre Continental de Pueblos y Organizaciones Indígenas en territorio mapuche, en Mar del Plata,Argentina, en 2005, ${ }^{3}$ se concluyó que los pueblos indígenas tienen su propia visión de desarrollo, sustentada en criterios de solidaridad entre los seres humanos y en un profundo respeto a la Madre Tierra. No están de acuerdo con la idea ni el modelo económico

${ }^{3}$ Cumbre Continental de Pueblos y Organizaciones Indígenas, territorio mapuche, en Mar del Plata,

TEORÍA y PRAXIS

5 (2008: I23-136) 
¿Etnoturismo o

turismo indígena?

basado en la explotación del hombre por el hombre y de la naturaleza en su conjunto. Por lo tanto, rechazan la visión y el modelo económico impulsado actualmente por los Estados, en el que sólo se pretende crear trabajo para enfrentar la pobreza, violando los derechos humanos y atentando contra la naturaleza, y que además los ha ido despojando de sus tierras, territorios y recursos naturales y que no permite sus procesos de autonomía.

En el Encuentro Continental de Pueblos y Nacionalidades Indígenas del Abya Yala, en La Paz, Bolivia, en 2006, plantearon:

Vemos al imperialismo como fase superior del capitalismo, a través de sus distintas expresiones, como lo son el consumismo, el desgaste de los recursos naturales que conllevan a la destrucción de la biodiversidad, la transculturación de los pueblos que implica borrar nuestra esencia, la pérdida de nuestros valores ancestrales y la negación de la existencia de nuestros pueblos, convirtiéndose en la más terrible amenaza que se cierne sobre la vida y existencia de nuestro planeta. ${ }^{4}$

Con todo lo expuesto podemos comprender las formas de organización y de búsqueda que han tenido los distintos grupos étnicos tanto en México como en América Latina. Es importante resaltar las demandas enarboladas en sus actos, entre las cuales sobresalen el trabajo solidario, la necesidad de rescatar sus identidades pluriétnicas y un análisis crítico de su historia y de la sociedad contemporánea. De esta manera, cuando se pretenda comprender a las culturas indígenas, deberá hacerse a partir de sus planteamientos, sus necesidades y sus cosmovisiones. Entonces, al hablar de turismo indígena se hará desde sus propuestas y no desde la visión del ajeno, del externo. En este sentido, lo que ellos llaman turismo indígena surge de las reuniones y cumbres mencionadas $y$, con base en este concepto, pretenden promover microempresas de turismo.

Argentina, del 2 al 4 de noviembre de 2005. Disponible en http://www.cumbrecontinentalindigena. org/declaracion.php, consultada el 30 de mayo de 2007.

${ }^{4}$ Encuentro Continental de Pueblos y Nacionalidades Indígenas del Abya Yala, en La Paz, Bolivia, del 8 al I 2 de octubre de 2006. Disponible en: http://www.abyayalobivia.org/ [2007, I 3 de junio]. 


\section{Turismo indígena}

Es la actividad donde las comunidades y pueblos indígenas ofrecen al visitante la oportunidad de compartir sus tradiciones, usos y costumbres, lo que permite revalorar y preservar sus elementos culturales además del reconocimiento de su identidad, en interacción cotidiana con su medio ambiente de manera sustentable. Al mismo tiempo se propicia un desarrollo integral comunitario consciente, responsable y solidario.

El turismo indígena se caracteriza por promover y fortalecer la sustentabilidad de los servicios ecoturísticos, como instrumentos efectivos para la conservación del patrimonio cultural y ambiental, que forman uno de los cimientos para el desarrollo económico comunitario, mediante el acceso a la información, el fortalecimiento de capacidades y las tecnologías apropiadas, fomentando en todo momento la participación activa y corresponsable de sus asociados. El turismo indígena es una empresa indígena de turismo que incide en la preservación de los recursos naturales, así como en el fortalecimiento de las bases para que sus miembros participen corresponsablemente en los asuntos de política ambiental y turística.

Las microempresas indígenas dedicadas al sector turismo nacen con la expectativa de fortalecer capacidades; son un puente estructurado y permanente con el que pueden lograr estrategias comunes de difusión, gestión, revaloración cultural, conservación y uso alternativo de los recursos naturales. Asimismo, se expresan como un espacio colegiado, plural y propositivo para influir en las políticas de uso y usufructo de la biodiversidad de sus territorios, además de la difusión, comprensión, entendimiento y apropiación de los derechos específicos de sus pueblos. Además, han iniciado un proceso de opinión, participación e incidencia en las leyes sobre turismo que se promulgan en el país, donde demuestran que los pueblos indios son capaces de planear, ejecutar y administrar empresas propias con base en los recursos con los que cuentan.

El principal rasgo de la actividad turística indígena es desarrollar en sus territorios microempresas sociales que rescaten sus tradiciones y su identidad cultural, sin verlo como mero folclore o como un espectáculo de interés para los turistas. Por el contrario, se busca destacar la grandeza del indio muerto (orígenes culturales) y, principalmente, del indio vivo, como el reapropiamiento y la revaloración de la cultura y el territorio, donde el trabajo ecológico lleva implícita la herencia cultural que han preservado como un medio de cohesión comunitaria y regional. 
¿Etnoturismo o

turismo indígena?

El trabajo de las microempresas en el interior de sus regiones es vasto y variado. Cada una, de acuerdo con su propia experiencia, interés y realidad, formula proyectos de conservación y aprovechamiento alternativo de la naturaleza, a la vez que capacita a sus miembros en derechos indígenas, revaloración cultural e identidad indígena. Así, de manera autónoma, y partiendo de los aspectos y acciones de mayor relevancia para cada comunidad, proyecto o microempresa, los integrantes fortalecen y enriquecen el quehacer de los pueblos indios como expresión de la cultura viva de nuestras raíces culturales.

La revaloración cultural es la piedra angular de su esencia, por lo cual integrantes de diferentes pueblos indígenas del país y del mundo trabajan convencidos de que el legado cultural y ambiental debe ser aprovechado para beneficiar el desarrollo de sus propias regiones y pueblos. En la búsqueda de un turismo con sello propio, las microempresas han impulsado proyectos de conservación de flora y fauna silvestre, de sus ecosistemas, para que los visitantes conozcan la vida de las múltiples especies y tengan la oportunidad de admirar la belleza del paisaje. En sus programas, resaltan su tierra encantada, la diversidad de la flora y la fauna y de su riqueza cultural, pero sobre todo propician un acercamiento a sí mismos y al visitante.

\section{Conclusiones}

Los conceptos de etnoturismo y de turismo indígena son diferentes, el primero hace hincapié en las actividades y beneficios de los usuarios o turistas, mientras que el segundo pone énfasis en la construcción participativa de las etnias para ofrecer un servicio de hospedaje, alimentación, guías especializados y prácticas cosmogónicas, cuyas características esenciales formen parte de su identidad cultural.

El turismo indígena es resultado de la toma de conciencia de las etnias a través de acuerdos locales, regionales, nacionales e internacionales, desde la década de los ochenta.Varios países de América Latina (Bolivia, Brasil,Argentina, Chile, Panamá y México, entre otros) se han reunido en cumbres para lograr acuerdos contra la discriminación histórica de la que han sido objeto estos pueblos por parte de la sociedad civil, del Estado y de los grandes capitales, y donde buscan opciones para mejorar sus condiciones materiales de vida. En el caso mexicano, existen varias organizaciones y redes indígenas (no oficiales) que pretenden ofrecer servicios turísticos con una orientación crítica, responsable y solidaria. 
El turismo indígena presenta las siguientes particularidades (RITA, 2007):

- Propicia interactuar, conocer, apreciar la naturaleza y la cultura de sus anfitriones, con el compromiso de respetar y participar en la conservación de sus recursos y con su diversidad biológica y cultural

- Maximiza las experiencias en forma responsable por parte de los turistas, microempresarios indígenas y guías locales

- Minimiza los impactos culturales y naturales

- Se distingue por su dimensión humana y cultural, orientada a fomentar encuentros interculturales de calidad y mutuo interés con los visitantes

- Proporciona códigos de ética para regular el comportamiento del turista y sus relaciones con la comunidad

- Busca dar un servicio competitivo sustentable sin perder su identidad cultural

- Espera que las comunidades prosperen y vivan dignamente, mejorando sus condiciones de vida y de trabajo

- Es una organización empresarial de autogestión de los recursos patrimoniales comunitarios, basados en las prácticas democráticas y solidarias de trabajo para la distribución de los beneficios generados

- Propicia una actividad solidaria, ambientalmente responsable, culturalmente enriquecedora y económicamente viable

- Preserva los recursos naturales y culturales, y fomenta su reconocimiento, difusión y observación en aras de una convivencia intercultural armoniosa

- Fortalece y desarrolla redes locales, regionales, nacionales e internacionales de turismo indígena, para un intercambio de experiencias entre comunidades y para el apoyo en el mercadeo y la promoción de cada destino turístico

Esta construcción participativa de diversos pueblos indígenas está en constante proceso de elaboración. Es un punto de partida para seguir forjando otros aspectos que les permitan redefinirse, especializarse y certificarse como microempresarios en el ramo turístico.Aún resta un sinfín de tareas por plantear: aquellas orientadas hacia una precisión conceptual, al trabajo técnico 
¿Etnoturismo o

turismo indígena?

y operativo, a la capacitación para su certificación, a los conocimientos básicos legales y a su vinculación con organismos oficiales para el desarrollo de sus I36 tareas administrativas.

\section{FUENTES CONSULTADAS}

ANPIBAC (1979). La educación indígena bilingüe bicultural. Conclusiones del Primer Seminario. Oaxtepec: Alianza Nacional de Profesionistas Indígenas Bilingües, A.C., 162 p.

Bonilla, Ángel (2004).“'La II Cumbre Continental de los Pueblos y Nacionalidades Indígenas de Abya Yala (Quito, 2004)”. oSAL, V, I 5, septiembre-diciembre, 257-266. Disponible en http://osal.clacso.org/espanol/html/osal I5/ACI5Bonilla.pdf [2007, I 3 de junio].

Centro Ceremonial Mazahua [en línea]. Disponible en: http://wwwabyayala. org/main_ccl-htm [2007, I5 de junio]

Cumbre Continental de Pueblos y Organizaciones Indígenas (2005) [en línea].Territorio Mapuche, Mar de Plata,Argentina, 2005. Disponible en: http://www. cumbrecontinentalindigena.org/declaracion.php [2002, 30 de mayo]

Daltabuit Godas, Magali (2005). Sustentabilidad y ecoturismo en Tres Garantías, Quintana Roo. México: Universidad Nacional Autónoma de México.

"Historia de un UNPFI" (2006) [en línea] UNPFII. Disponible en: http://www. un.org/esa/socdev/unpfii/es/history.html [2007, junio].

Encuentro Continental de Pueblos y Nacionalidades Indígenas del Abya Yala, en La Paz, Bolivia (2006). Disponible en: http://www.abyayalabolivia. org/ [2007, I 3 de junio].

Lagunas, David (2007). Antropología y turismo: claves culturales y disciplinares. México: Plaza y Valdés.

RITA (2007a). Acuerdos del Taller Identidad, Certificación, Turismo y Pueblos Indios, Xochitlán, Puebla, agosto de 2007.

- (2007b).Acuerdos del Taller Identidad, Certificación, Turismo y Pueblos Indios, Edzná, Campeche, octubre de 2007.

Sectur (2004). Turismo alternativo, una nueva forma de hacer turismo. México: Secretaría de Turismo, serie Turismo Alternativo, fascículo I. Disponible en http://www.metztitlan.com.mx/_ReservaBiosfera/_Fasciculos/ I turismoalternativo.pdf [2007, marzo]. 